\title{
OS HÁBITOS DE CONSUMO DAS GERAÇÕES Y E Z: A DIMENSÃO AMBIENTAL NOS CONTEXTOS FAMILIAR E ESCOLAR
}

\author{
Edson Roberto Scharf \\ Docente e pesquisador do PPGAD/FURB \\ artigoes@gmail.com \\ Célio Paulo Rosa \\ Mestrando em Administração na FURB \\ cprosa@gmail.com \\ Denise Oliveira \\ Mestranda em Administração na FURB \\ denol@gmail.com
}

Recebido em 26/setembro/2011 Aprovado em 19/agosto/2012

\section{RESUMO}

O objetivo deste trabalho foi identificar se a aquisição do conhecimento sobre sustentabilidade pelas gerações Y e Z ocorre no contexto familiar ou no escolar. Classificado como quantitativo, de caráter descritivo, o estudo se valeu de questionário adaptado de Bhattacharya; Korschun; Sen (2009). Participaram estudantes dos cursos de nível médio e superior de dois campi de institutos federais, localizados em Santa Catarina e no Rio Grande do Sul. Os resultados principais mostraram que as gerações Y e Z enfatizam, respectivamente, a escola e a família como responsáveis pelo ensino de sustentabilidade; que para ambas as gerações a família tem mais condições de ensinar o tema sustentabilidade; que as duas gerações entendem que os exemplos de boas práticas relacionadas à sustentabilidade devem vir da escola. As conclusões permitem sugerir que a aquisição de conhecimento sobre sustentabilidade nos contextos familiar e escolar pode ser importante precedente para hábitos de consumo e que as organizações devem desenvolver comunicação ao mercado, que favoreça a construção adequada de processos de decisão de compra e consumo, atuais e futuros.

Palavras-chave: Sustentabilidade. Geração Y. Geração Z. Marketing.

\section{ABSTRACT}

The aim of this study was to identify if the acquisition of knowledge about sustainability for $Y$ and $Z$ generations occurs in family or school contexts. Characterized as quantitative and descriptive, this study used a questionnaire adapted from Bhattacharya; Korschun; Sen (2009). Students of high school and graduation courses from two campi of federal institutes, located in Santa Catarina and Rio Grande do Sul, participated in this study. The main results showed that $Y$ and $Z$ generations emphasize, respectively, school and family as responsible for teaching sustainability; that for both generations the family is better able to teach the topic of sustainability; and both $Y$ and $Z$ generations understand that examples of good practices related to sustainability must come from the school. The findings allow to suggest that the acquisition of knowledge about sustainability in family and school contexts may be important precedent in consumer habits and that organizations should develop communication with the market in order to favor a proper construction of purchase and consumption process, current and future.

Key words: Ecological products, green marketing, consumer behavior, responsible consumption, attitude. 


\section{INTRODUÇão}

O crescimento dos mercados e a diversificação na produção de bens e serviços forçaram as empresas a ampliar o estímulo ao consumo, processo que pode gerar forte impacto ambiental. Para Basílio e Felix (2010), é um resultado que aponta a necessidade de educar as pessoas quanto ao consumo consciente.

A formação do caráter do indivíduo se dá pela influência de duas instituições que sobrevivem à modernidade: a escola e a família. Para Rego (2003), ambas compartilham funções sociais, políticas e educacionais, na medida em que influenciam a formação do cidadão e contribuem para ela. Essas instituições são responsáveis pela transmissão e construção do conhecimento. Na família, o compartilhamento do conhecimento fomenta os processos de socialização e proteção, com desenvolvimento nos planos social, cognitivo e afetivo. Na escola, os conteúdos curriculares asseguram a instrução e a busca do conhecimento. Entre os assuntos estudados, um tem recebido atenção - o da sustentabilidade. Segundo o autor, o envolvimento e o aprendizado sobre o tema são acontecimentos que ocorrem em ambos os ambientes, familiar e escolar.

No presente momento, as gerações $\mathrm{Y}$ e $\mathrm{Z}$, pessoas nascidas entre os anos de 1977 e 1995, e após 1996, respectivamente, estão acessando o mercado de trabalho ou adquirindo formação acadêmica para esse fim, condição que lhes permitirá acesso mais franco ao consumo.

O objetivo deste trabalho éidentificar se o aprendizado sobre sustentabilidade é adquirido pelas gerações Y e Z com maior ênfase no contexto familiar ou no escolar.

O estudo está estruturado em cinco seções: na segunda, apresenta-se a fundamentação teórica; na terceira, a metodologia adotada neste trabalho; na quarta, mostram-se os dados coletados e sua análise; na quinta seção são apontadas as considerações finais, incluindo uma síntese dos principais resultados, conclusões e sugestões para futuras pesquisas.

\section{FUNDAMENTAÇÃo TEÓRICA}

A abordagem ambiental é importante ao se considerar que o futuro da humanidade depende da relação estabelecida entre homem e natureza que, para Bessa e Costa (2009), contrapõe as necessidades decorrentes do consumo e a escassez dos recursos naturais. Com base nesse contexto, destacam-se a seguir termos relevantes para o entendimento do estudo.

\subsection{SuSTENTABILIDAdE}

Oconceito de sustentabilidadecomeçou aserdiscutido em 1972 na Conferência das Nações Unidas sobre o Meio Ambiente Humano, realizada em Estocolmo, dita como a primeira conferência das Nações Unidas sobre o meio ambiente e a primeira grande reunião internacional para discussão das atividades humanas em relação ao meio ambiente. Os resultados da conferência apontaram uma incompatibilidade entre o desenvolvimento sustentável e os padrões de produção e consumo vigentes à época e propuseram que o desenvolvimento ocorresse de forma sensata.

Apesar de haver muito debate sobre a interpretação e o uso da terminologia 'desenvolvimento sustentável' e 'sustentabilidade', segundo Gonçalves-Dias, Teodósio e Barbieri (2007), existe unanimidade no reconhecimento do meio ambiente como foco maior das atenções, quando se trata do tema sustentabilidade.

O conceito popular sobre sustentabilidade tornase mais compreensível quando formulado com base em três dimensões propostas por Elkington (1990), o denominado triple bottom line: a ambiental, a econômica e a social. No entendimento do autor, a sustentabilidade é um princípio que assegura que as ações de hoje não irão minimizar as opções ambientais, econômicas e sociais no futuro. Holland (2003) complementa dizendo que, mesmo que as gerações atuais não estejam aptas para prever necessidades futuras, o desenvolvimento que está por vir só será possível com os recursos e a capacidade do meio ambiente de assimilar impactos. Avançando no conceito, diversos autores (HUANG e RUST, 2011; BHATTACHARYA, KORSCHUN e SEN, 2009; SAVITZ e WEBER, 2006) sugerem que empresa sustentável é aquela que cria lucro para os acionistas enquanto protege o meio ambiente e melhora a vida das pessoas em seu entorno. 
Não é possível resolver os complexos problemas ambientais e reverter suas causas sem que ocorram mudanças radicais, segundo Leff (2001). Essas alterações deverão acontecer nos sistemas de conhecimento, valores e comportamentos gerados pela dinâmica de racionalidade existente, com base no aspecto econômico do desenvolvimento, segundo o autor. Para Scharf e Cunha (2011), o esforço mercadológico das organizações está se dirigindo para a oferta de bens e serviços que sejam ecologicamente corretos. Há distinção entre produtos considerados sustentáveis e os demais; os primeiros obtêm sucesso porque são criados para atender às questões econômicas, ambientais e sociais (SCHARF; CUNHA, 2011). Para diversos autores (FREITAS, JABBOUR e GOMES, 2011; GONÇALVES-FILHO et al., 2009), o desafio de gerenciar a dimensão ambiental é sistêmico, absorvendo talentos de todas as áreas, evidenciando o fato de que estabelecer boas relações com a comunidade é prioridade organizacional.

\subsection{Sustentabilidade Ambiental no conteXto FAMILIAR}

A família é o primeiro grupo do convívio humano e por isso tem sido a influência mais relevante para o desenvolvimento da personalidade e do caráter da pessoa. Para Mainardi e Pessotto (2010), a educação bemsucedida da criança servirá de apoio e embasamento à sua criatividade e ao seu comportamento produtivo quando for aluno na escola e adulto na sociedade. Segundo os autores, explicar às crianças os comportamentos aceitáveis e os que não devem ser repetidos promove a inserção delas em uma escala de valores adotada pela família. Considerando que o ser humano vive em constante aprendizado, a família constitui um potencial local de estímulo às boas práticas ambientais. Para os autores, é ela que decide, desde cedo, o que os filhos precisam aprender, quais as instituições que devem frequentar e o que é importante saber para tomar decisões que os beneficiem no futuro.

Para Leff (1999), a orientação ambiental, inclusive familiar, é vista como uma ferramenta centrada na perspectiva da sustentabilidade e que adquire um sentido estratégico na condução do processo rumo a uma sociedade sustentável. De acordo com o autor, a educação para o consumo é elemento-chave na conscientização da população. Para Pires e Bromberger (2007), a família consiste na instituição norteadora para a formação do indivíduo, quer no aspecto social, educacional ou cultural.

Atualmente, a abordagem de assuntos relacionados à sustentabilidade está presente nas famílias em função dos meios de comunicação. Práticas diárias sobre como usar os recursos naturais de forma responsável podem influenciar no desenvolvimento da consciência da cidadania das crianças. Na compreensão de Rego (2003), a criança leva para a escola e para a vida os valores que aprendeu em casa; logo, a educação em casa a prepara para o convívio com colegas e educadores.

\subsection{SustentabilidAdE AMbiental no CONTEXTO} ESCOLAR

A educação ambiental é definida pelo art. $1^{\circ}$ da Lei $\mathrm{n}^{\circ}$ 9.795, de 1999, como o conjunto de processos por meio do qual o indivíduo e a coletividade constroem valores sociais, conhecimentos, habilidades, atitudes e competências voltadas para a conservação do meio ambiente. No artigo $2^{\circ}$, a mesma lei institui que a educação ambiental é um componente essencial e permanente da educação nacional, devendo estar presente, de forma articulada, em todos os níveis e aspectos do processo educativo, em caráter formal e não-formal.

Nesse contexto, o educador tem a função de mediador na construção de referenciais ambientais. Para Jacobi (2003), a educação ambiental assume uma função transformadora, em que a responsabilização compartilhada pelos indivíduos é objetivo essencial para promover um novo desenvolvimento: o sustentável. Conforme Mainardi e Pessotto (2010), os docentes devem atuar nas escolas interdisciplinarmente, levando os alunos a compreender a ecologia (consciência de que é preciso preservar, evitar desperdícios e economizar os recursos naturais para as gerações futuras). Educar para a sustentabilidade é, fundamentalmente, educar para uma vida sustentável (GADOTI, 2008). Para o autor, educar ambientalmente é mover todos os recursos disponíveis, tendo como objetivo a preservação do 
planeta e, consequentemente, a saúde do ser humano. A educação ambiental deve ser vista como um processo de permanente aprendizagem, que valoriza o conhecimento e forma cidadãos com consciência ambiental (SCHARF; SORIANO-SIERRA, 2006; JACOBI, 2003).

Entendem Scharf e Soriano-Sierra (2006) que, por seu lado, o aluno deve ser participativo nas práticas ambientais, desenvolvendo o seu próprio conhecimento e a consciência de que por meio de pequenas ações pode transformar seu ambiente e, por conseguinte, ajudar a melhorar o planeta. Maia e Pires (2011) compreendem que a consciência ecológica deve estar na essência das decisões e ações humanas e, para chegar nesse nível, a educação para a sustentabilidade é fundamental. A prática ambiental deve ser voltada para mudanças de posturas, hábitos e pensamentos ambientais para a formação de uma cidadania consciente (MAINARDI; PESSOTTO, 2010).

Um estudo de Bessa e Costa (2009), realizado com professores, gestores e estudantes de Gurupi (TO), identificou a percepção da comunidade escolar sobre os princípios de uma educação transformadora e cidadã. A sustentabilidade foi percebida como forma de aproveitar os recursos naturais de forma mais equilibrada, no entanto parte dos sujeitos pesquisados ainda a dissocia do meio social. Os professores reconhecem a necessidade de estar mais bem capacitados nos aspectos abordados na pesquisa. De acordo com Bursztyn e Bartholo Jr. (2001), é necessário que se busque uma reorientação do ensino no sentido do desenvolvimento sustentável. O desafio consiste em formular uma educação ambiental crítica e inovadora nos níveis formal e informal. Hopkins e McKeown (2002) defendem que reorientar a educação é uma expressão capital para entender a proposta de educação para a sustentabilidade.

\subsection{GeraÇões Y E Z}

O conceito de geração engloba o conjunto de indivíduos nascidos em uma mesma época, influenciados por um contexto histórico que determina comportamentos e causa impacto direto na evolução da sociedade. De acordo com Vasconcelos et al. (2009), a história de uma geração está baseada em um conjunto de vivências comuns, valores, visão de vida, cenário sociopolítico e proximidade de idades. Para os autores, as particularidades das diferentes gerações influenciam na vivência social dos indivíduos. Nas últimas décadas, a classificação dos indivíduos por geração e estilo de consumo se tornou comum, especialmente na área de marketing.

Para Bakewell e Mitchell (2003), as pessoas, independentemente da geração a que pertencem, vivenciam experiências, entre as idades de 5 a 18 anos, que afetam a sua visão de vida, especialmente em relação ao consumo e ao trabalho. Consoante diversos autores (HUDSON, 2010; OSAJIMA; STERNQUIST; MANJESHWAR, 2010; SHAH, 2009; HANZAEE; AGHASIBEIG, 2008), as gerações mais recentes são os baby boomers (nascidos entre 1941-1960, a maior parte nos países ocidentais, com forte impacto na economia da sociedade americana); a geração $X$ (nascidos entre 1961-1976, que trazem como característica o controle da natalidade, a decisão por famílias menores e a presença na recessão da década de 80); a geração Y (nascidos entre 1977-1995, também conhecidos como geração millennium, são os filhos dos baby boomers ou da geração X). Para Hanzaee e Aghasibeig (2008), esta última geração busca viver intensamente cada experiência, preza a informalidade no vestuário e na comunicação e está sempre procurando aumentar sua rede de relacionamento. Como sempre tem pressa, a geração $\mathrm{Y}$ responde menos aos modelos tradicionais de gerenciamento. Por último, tem-se a geração Z (nascidos após 1996), sucedânea das gerações X e Y, porém não carrega as bagagens cultural, social, política, econômica e ideológica das anteriores. Seus representantes buscam novos desafios, mas evitam os riscos (SHAH, 2009). Por se formar na internet, celulares e videogames, é denominada de geração zapping. Apresenta problemas de interação social, com o comportamento orientado por informação em tempo real. Uma implicação disso, segundo Shah (2009), é que o volume intenso de informação se torna obsoleto em pouco tempo, gerando desconforto e insatisfação.

Embora não exista uma definição única quanto ao período histórico e cronológico de cada uma das gerações, devido à variedade de entendimento de pesquisadores, a 
Tabela 1 apresenta a composição de cada grupo, segundo diversos autores: gerações permeiam ambos os espaços.

A amostra deste estudo é composta por 264 discentes do campus Concórdia e 322 discentes do

Tabela 1 - Composição das gerações de acordo com diferentes autores campus Sertão.

\begin{tabular}{c|c|c}
\hline Geração & Autores & $\begin{array}{c}\text { Nascimentos dos } \\
\text { membros }\end{array}$ \\
\hline Seniors & Wada; Carneiro (2010) & antes de 1925 \\
\hline Builder & Wada; Carneiro (2010) & 1926 a 1945 \\
\hline Tradicional & Vasconcelos et al. (2009) & antes de 1945 \\
\hline \multirow{3}{*}{ Baby Boomers } & Osajima et al. (2010); Shah (2009) & 1941 a 1960 \\
\cline { 2 - 3 } & Vasconcelos et al. (2009) & 1946 a 1964 \\
\hline \multirow{3}{*}{ Geração X } & Wada; Carneiro (2010) & 1946 a 1964 \\
\cline { 2 - 3 } & Osajima et al. (2010); Shah (2009) & 1961 a 1976 \\
\cline { 2 - 3 } & Vasconcelos et al. (2009) & 1965 a 1977 \\
\hline \multirow{3}{*}{ Geração Y } & Hudson (2010); Wada; Carneiro (2010) & 1965 a 1981 \\
\cline { 2 - 3 } & Osajima et al. (2010); Shah (2009) & 1977 a 1992 \\
\cline { 2 - 3 } & Vasconcelos et al. (2009) & após 1978 \\
\cline { 2 - 3 } & Wada; Carneiro (2010) & 1982 a 2000 \\
\hline \multirow{3}{*}{ Geração Z } & Mowen; Minor (2003) & 1980 a 1995 \\
\cline { 2 - 3 } & Osajima et al. (2010) e Sahah (2009) & após 1992 \\
\cline { 2 - 3 } & Wada; Carneiro (2010) & após 2001 \\
\hline
\end{tabular}

Fonte: Pesquisa bibliográfica

No campus do

IFC Concórdia

os cursos

e n volvidos

foram: Técnico emAgropecuária; Técnico em A 1 i m e n tos ( $\mathrm{a}$ m b 0 s integrados ao Ensino Médio); Técnico em Informát i c a ; M e d i c i n a Ve terinária ; Licenciatura em Matemát ic a ; Engenharia de Alimentos. No campus do IFC Sertão os cursos

\section{Metodologia}

Este estudo é classificado como quantitativo, de caráter descritivo, segundo os preceitos de Hair (2005). Utilizou-se a tipologia cronológica de Mowen e Minor (2003), a qual sugere que a geração Y é composta por nascidos entre 1980 e 1995; e a geração Z, de nascidos a partir de 1996.

A população desta pesquisa foi composta por alunos matriculados nos cursos técnicos de nível médio e nos cursos superiores do Instituto Federal de Educação, Ciência e Tecnologia Catarinense, doravante denominado IFC, dos campi Concórdia (SC) e Sertão (RS), no primeiro semestre do ano de 2011. A amostra constituiuse da totalidade de alunos presentes na sala de aula no momento da aplicação do questionário. Não se tem a intenção de discutir no trabalho a respeito das diferenças entre discentes dos níveis superior e médio, posto que as envolvidos foram: Técnico em Agropecuária (integrado ao Ensino Médio); Agronomia; Licenciatura em Ciências Agrícolas; Tecnologia em Agronegócio; Tecnologia em Alimentos; Tecnologia em Gestão Ambiental; Zootecnia. Do total de respondentes, após identificação, foram descartados dez por serem participantes da geração X. Ao final, a amostra totalizou 578 respondentes válidos.

Para a coleta dos dados utilizou-se um questionário estruturado, tendo por base a descrição de Bhattacharya; Korschun; Sen (2009), que explorou a conscientização dos jovens em relação à dimensão ambiental do tema sustentabilidade como influenciador no processo de compra e consumo. Para identificar o entendimento e o envolvimento das gerações $\mathrm{Y}$ e $\mathrm{Z}$ no aprendizado da sustentablidade, especificamente quanto à dimensão ambiental, determinando o contexto em que essa abordagem ocorre ou deveria ocorrer (se familiar ou escolar), o questionário foi dividido em três etapas. A 
primeira delas abrangeu informações sobre o perfil dos respondentes. A segunda contemplou onze questões, com respostas optativas do tipo 'a' ou 'b' relativas ao ambiente familiar ou escolar em que ocorre ou deveria ocorrer a abordagem da sustentabilidade ambiental. A terceira etapa reuniu 30 afirmativas com o uso da escala do tipo Likert, distribuídas em cinco dimensões. Esta última fase permitiu aos respondentes a opção de apontamento do nível de concordância com uso de uma escala intervalar de 1 (discordo totalmente) a 7 (concordo totalmente), com cinco dimensões (sustentabilidade; aprendizado; família; escola; atividade).

A variável 'sustentabilidade' referiu-se ao grau de entendimento dos jovens sobre a dimensão ambiental do conceito de sustentabilidade. A variável 'aprendizado' relacionou-se à avaliação do envolvimento dos jovens em atividades de aprendizagem sobre a sutentabilidade. A variável 'família' identificou se a abordagem sobre a sustentabilidade ocorre ou deveria ocorrer no contexto familiar. A variável 'escola' identificou se a abordagem sobre a sustentabilidade ocorre ou deveria ocorrer no contexto escolar. A variável 'atividade' avaliou o envolvimento dos jovens em ações práticas sobre a sutentabilidade. Na Tabela 2, estão representadas as principais afirmativas de cada variável:
Tabela 3 - Quantidade de alunos pesquisados por nível e por campus

\begin{tabular}{|c|c|c|c|c|}
\hline Campus & Curso & Respondentes & $\%$ & $\begin{array}{c}\text { Quantidade } \\
\text { por campus }\end{array}$ \\
\hline \multirow{2}{*}{ Concórdia } & Ensino Médio & 220 & 38,06 & \multirow{2}{*}{259} \\
\cline { 2 - 4 } & Ensino Superior & 39 & 6,75 & \\
\hline \multirow{2}{*}{ Sertão } & Ensino Médio & 172 & 29,76 & \multirow{2}{*}{319} \\
\cline { 2 - 4 } & Ensino Superior & 147 & 25,43 & \\
\hline \multicolumn{2}{|c|}{ Totais } & 578 & 100 & 578 \\
\hline
\end{tabular}

Fonte: Elaborada pelos autores.

\section{Desenvolvimento: Resultados da Pesquisa}

Neste estudo os dados foram coletados entre estudantes pertencentes às gerações $\mathrm{Y}$ e $\mathrm{Z}$, conforme entendimento de Mowen e Minor (2003). Os alunos respondentes frequentam cursos de nível médio e de nível superior, conforme descritos na Tabela 3.

Quanto ao gênero, a Tabela 4 mostra que o maior número de respondentes é do sexo masculino, com 392 participantes, enquanto 195 são do sexo feminino.

Tabela 2 - Relação das dimensões com as descrições e questões principais.

\begin{tabular}{|c|c|c|}
\hline Variável & Descrição & Principais afirmativas de cada dimens: \\
\hline Sustentabilidade & $\begin{array}{c}\text { Entendimento dos jovens sobre o } \\
\text { conceito }\end{array}$ & $\begin{array}{c}\text { Tenho conhecimento sobre práticas de } \\
\text { sustentabilidade }\end{array}$ \\
\hline Aprendizado & $\begin{array}{c}\text { Envolvimento dos jovens em } \\
\text { atividades de aprendizagem sobre a } \\
\text { sustentabilidade }\end{array}$ & $\begin{array}{c}\text { Busco me informar sobre a destruição d } \\
\text { natureza e do planeta }\end{array}$ \\
\hline Familia & $\begin{array}{c}\text { Envolvimento da familia na } \\
\text { abordagem da sustentabilidade }\end{array}$ & $\begin{array}{c}\text { A família deve ensinar sobre como consur } \\
\text { sem agredir o meio ambiente }\end{array}$ \\
\hline Escola & $\begin{array}{c}\text { Envolvimento da escola na } \\
\text { abordagem da sustentabilidade }\end{array}$ & $\begin{array}{c}\text { A escola tem mais condiç̃os estruturais } \\
\text { ensinar sobre questões ambientais }\end{array}$ \\
\hline Atividade & $\begin{array}{c}\text { Envolvimento dos jovens em } \\
\text { práticas ambientais }\end{array}$ & $\begin{array}{c}\text { Procuro contribuir para a melhoria da } \\
\text { qualidade de vida do planeta }\end{array}$ \\
\hline
\end{tabular}

Tabela 4 - Gênero dos respondentes por campus

\begin{tabular}{|c|c|c|c|c|c|}
\hline Campus & Gênero & Respondentes & $\%$ & $\begin{array}{c}\text { Total por } \\
\text { gênero }\end{array}$ & $\begin{array}{c}\% \text { por } \\
\text { gênero }\end{array}$ \\
\hline Concórdia & Masculino & 151 & 26,12 & \multirow{2}{*}{387} & \multirow{2}{*}{66,95} \\
\cline { 1 - 4 } Sertào & Masculino & 236 & 40,84 & & \\
\hline Concórdia & Feminino & 107 & 18,51 & \multirow{2}{*}{191} & \multirow{2}{*}{33,05} \\
\cline { 1 - 3 } Sertão & Feminino & 84 & 14,53 & & \\
\hline \multicolumn{2}{|c|}{ Totalis } & 578 & 100 & 578 & 100 \\
\hline
\end{tabular}

Fonte: Elaborada pelos autores.
Analisaram-se os dados com métodos de estatística descritiva; qui quadrado, com uso do software SPSS; alfa de Cronbach e matriz de correlação de Pearson, com uso do software LhStat 1.3.
Fonte: Elaborada pelos autores.

53 CONTEXTUS Revista Contemporânea de Economia e Gestão. Vol. 10 - № 1 - jan/jun 2012
Identificaram-se e descartaram-se dez respondentes participantes da geração $X$. Considerados válidos, foram 418 integrantes da geração Y (71,09\%) e 160 membros da geração Z (27,21\%), conforme Tabela 5, em que também 
se observa a procedência e a quantidade dos respondentes por campi.

Tabela 5 - Classificação por geração

\begin{tabular}{|c|l|c|c|c|c|}
\hline \multirow{2}{*}{ Geração } & Campus & Respondentes & $\%$ & $\begin{array}{c}\text { Total por } \\
\text { geração }\end{array}$ & $\begin{array}{c}\text { \% por } \\
\text { geração }\end{array}$ \\
\hline \multirow{2}{*}{ Y } & Concórdia & 201 & 34,78 & \multirow{2}{*}{418} & 72,31 \\
\cline { 2 - 4 } & Sertão & 217 & 37,54 & & \\
\hline \multirow{2}{*}{$Z$} & Concórdia & 58 & 10,03 & 160 & 27,69 \\
\cline { 2 - 4 } & Sertão & 102 & 17,65 & & 100 \\
\hline \multicolumn{2}{|c|}{ Totais } & 578 & 100 & 578 & \multirow{2}{*}{} \\
\hline
\end{tabular}

Fonte: Elaborada pelos autores.

A Tabela 6 apresenta 11 questões com os resultados de cada geração e os cálculos de qui-quadrado e P-value. A escala pode ser admitida como confiável, dado o valor de alfa de Cronbach obtido (alfa igual a 0,847 e alfa de Cronbach de 0,851, com base nos pontos padronizados). $\mathrm{O}$ alfa de Cronbach constitui um indicador estatístico de fidedignidade de um instrumento psicométrico. De acordo com Hair et al. (2005), o limite inferior aceito para o alfa de Cronbach é de 0,70, podendo diminuir para 0,60 em pesquisas exploratórias. Os testes qui-quadrado e P-value foram realizados visando verificar a existência de associação entre as variáveis e para assegurar a significância dos resultados obtidos. $\mathrm{O}$ valor de $\mathrm{P}<0,05$ é, segundo Gauvreau e Pagano (1994), tradicionalmente fixado para estudos dessa ordem.

Comapergunta sobre de quem seria a responsabilidade no ensino sobre sustentabilidade obtiveram-se respostas aproximadas. Existe associação entre as variáveis 'escola' e 'família' e as gerações estudadas $(\mathrm{P}<0,05)$, com baixa diferença entre a geração $\mathrm{Y}$ e a geração $\mathrm{Z}$ quanto à importância da ‘escola’ e da ‘família’ no aprendizado da sustentabilidade. Essa relação é verificada na frequência das respostas: enquanto na geração Y o papel da escola obteve $54,5 \%$ das respostas, na geração $\mathrm{Z}$ a família se destaca com 56,3\% das respostas. Na pergunta acerca do local adequado para se aprender sobre o tema, os estudantes afirmaram ser a escola, com percentual superior na geração Z (66,9\%, ante os 62,7\% da geração Y). Com P-value de 0,348 , os resultados demonstram que não há uma relação linear estatisticamente significativa. Para Gadotti (2008), é preciso passar de uma responsabilidade diluída para uma ação compartilhada, com o exercício da sustentabilidade na vida diária, tanto na família quanto no trabalho, prática esta que passa pela escola. Corroboram esse pensamento Bursztyn e Bartholo Jr. (2001), para quem é necessário buscar uma reorientação do ensino no sentido do desenvolvimento sustentável.

Quando questionadas a respeito da capacidade de ensino sobre o tema sustentabilidade, ambas as gerações entenderam que a família é o espaço adequado para o aprendizado. Com P-value de 0,280, os resultados apontam para uma relação linear estatisticamente não significativa. Para Mainardi e Pessotto (2010), a família, como primeiro grupo de convívio, influencia de maneira relevante o desenvolvimento das pessoas. Quanto ao ambiente mais adequado para a aprendizagem da separação do lixo, a escola apresentou superioridade no entendimento da geração Y, com 68,7\%; para a geração $\mathrm{Z}$, no entanto, a família constitui o ambiente adequado, com 68,4\%. Há relação significativa entre as variáveis, apontada pelo P-value inferior a 0,05.

Ao serem questionados se a escola deve envolver a família nos projetos de sustentabilidade ambiental ou se é a família que deve procurar a escola, novamente se observou que os respondentes entendem ser a família a instituição que deve envolver a escola. Não houve relação linear estatisticamente significativa nos resultados (P-value de 0,659). A geração Z atribuiu maior percentual a essa resposta, com 81,8\%, enquanto a geração $Y$ apresentou 54,5\%.

Quanto à responsabilidade de dar exemplos sobre práticas de sustentabilidade, os respondentes de ambas as gerações entenderam ser da escola essa função, com $80 \%$ para a geração Y e $71 \%$ para a geração Z. Foi apresentada relação significativa entre as variáveis, com o P-value inferior a 0,05. Para Mainardi e Pessotto (2010), a escola tomou proporções nunca antes imaginadas no processo de humanização e de preparo das pessoas, ainda que a instituição reclame da ausência da família no acompanhamento do desenvolvimento das crianças e dos adolescentes, especialmente no que respeita à dificuldade que encontra em transmitir valores éticos e morais para a convivência em sociedade. Para Gadotti (2008), a escola, os professores e a educação em geral têm importância 
capital na sociedade denominada 'aprendizagem global', em que ora se vive. Esses entendimentos também parecem claros às gerações Y e Z.

Quando indagadas se a aprendizagem de como consumir sem agredir o meio ambiente ocorreria no ambiente da escola ou da família, ambas as gerações optaram pelo ambiente familiar, com percentuais de 77,3\% para a geração Y e 70,6\% para a geração Z. Para Mainardi e Pessotto (2010), o papel da família é fundamental, pois é ela que decide o que os filhos devem aprender, o que é necessário para tomar decisões, a sua inserção no ambiente escolar e outros fatores determinantes para o seu desenvolvimento social. Na questão referente ao conhecimento sobre o consumo de energia elétrica, os respondentes também entenderam que a família é mais indicada para o ensino, com 63,4\% na geração Y e 53,7\% na geração Z.

Na indagação sobre se o jovem aprendeu mais sobre a preservação do meio ambiente na escola ou com a família, despontou uma relação significativa entre as variáveis, com o P-value inferior a 0,05. Houve vantagem pequena em prol da família em ambas as gerações (Y com 57,9\% e Z com 68,1\%). Mainardi e Pessotto (2010) defendem que a família é o primeiro grupo de convívio humano e, por isso, tem sido o mais poderoso influenciador do desenvolvimento pessoal.

Sobre o aprendizado da correta utilização da água, ambas as gerações indicaram ser uma incumbência da escola (enquanto a geração Y participou com 57,7\% das respostas, a geração Z teve participação de 56,9\%). É preciso reforçar, no entendimento de Gadotti (2008), a ideia de que diferentes abordagens cotidianas podem ser tratadas pela escola de modo diversificado, diferindo, assim, da família.

Tabela 6 - Posição das duas gerações quanto à influência da escola ou da família

\begin{tabular}{|c|c|c|c|c|c|c|c|c|c|c|}
\hline & & $\mathbf{Y}$ & & & & $\mathbf{Z}$ & & & quadrado & value \\
\hline QUESTÕES & escola & $\%$ & família & $\%$ & escola & $\%$ & família & $\%$ & & \\
\hline $\begin{array}{l}1 \text { - } \\
\text { Responsabilidade } \\
\text { para a educação } \\
\text { sobre } \\
\text { sustentabilidade }\end{array}$ & 228 & 54,5 & 190 & 45,5 & 70 & 43,7 & 90 & 56,3 & 5,399 & 0,020 \\
\hline $\begin{array}{l}2 \text { - Local para } \\
\text { aprender sobre } \\
\text { sustentabilidade }\end{array}$ & 262 & 62,7 & 156 & 37,3 & 107 & 66,9 & 53 & 33,1 & 0,882 & 0,348 \\
\hline $\begin{array}{l}3 \text { - Quem tem } \\
\text { mais condições de } \\
\text { ensinar } \\
\text { sustentabilidade }\end{array}$ & 170 & 40,7 & 248 & 59,3 & 73 & 45,6 & 87 & 54,4 & 1,166 & 0,280 \\
\hline $\begin{array}{l}4-\text { Ambiente } \\
\text { para aprender } \\
\text { sobre separação } \\
\text { do lixo }\end{array}$ & 287 & 68,7 & 131 & 31,3 & 132 & 31,6 & 28 & 68,4 & 11,114 & 0,001 \\
\hline $\begin{array}{l}5 \text { - Quem deve } \\
\text { estar envolvido } \\
\text { no ensino da } \\
\text { sustentabilidade }\end{array}$ & 190 & 45,5 & 228 & 54,5 & 76 & 18,2 & 84 & 81,8 & 0,195 & 0,659 \\
\hline $\begin{array}{l}6 \text { - Quem deve } \\
\text { dar exemplo } \\
\text { sobre } \\
\text { sustentabilidade }\end{array}$ & 297 & 71,0 & 121 & 29,0 & 128 & 80 & 32 & 20 & 4,759 & 0,029 \\
\hline $\begin{array}{l}7-\text { Com quem } \\
\text { aprender a } \\
\text { consumir sem } \\
\text { agredir o meio } \\
\text { ambiente }\end{array}$ & 95 & 22,7 & 323 & 77,3 & 47 & 29,4 & 113 & 70,6 & 2,759 & 0,097 \\
\hline $\begin{array}{l}8 \text { - Com quem } \\
\text { aprender a } \\
\text { consumir menos } \\
\text { energia elétrica }\end{array}$ & 153 & 36,6 & 265 & 63,4 & 74 & 46,3 & 86 & 53,7 & 4,515 & 0,034 \\
\hline $\begin{array}{l}9 \text { - Com quem } \\
\text { aprendi sobre } \\
\text { preservação do } \\
\text { meio ambiente } \\
\end{array}$ & 176 & 42,1 & 242 & 57,9 & 51 & 31,9 & 109 & 68,1 & 5,078 & 0,024 \\
\hline $\begin{array}{l}10 \text { - Com quem } \\
\text { aprendi a } \\
\text { utilização correta } \\
\text { da água }\end{array}$ & 241 & 57,7 & 177 & 42,3 & 91 & 56,9 & 69 & 43,1 & 0,029 & 0,865 \\
\hline $\begin{array}{l}11-\text { Com quem } \\
\text { aprendi a evitar o } \\
\text { desmatamento }\end{array}$ & 252 & 60,3 & 166 & 39,7 & 57 & 35,7 & 103 & 64,3 & 28,286 & 0,000 \\
\hline
\end{tabular}

Fonte: Elaborada pelos autores. 
Na última questão, concernente ao aprendizado sobre o desmatamento, houve uma relação significativa entre as variáveis $(\mathrm{P}<0,05)$; a geração $\mathrm{Y}$ alcançou 60,3\%, com a opção ‘escola’ e a geração Z apresentou 64,3\% das respostas para a opção 'família'. A família e a escola, no entendimento de Mainardi e Pessotto (2010), são pontos de apoio e sustentação do ser humano. Para as autoras, quanto melhor for a parceria entre ambas mais significativos serão os resultados obtidos na formação da pessoa.

A Tabela 7 apresenta o cálculo da média descritiva representada pelas variáveis estudadas, utilizando os graus de ‘concordância', ‘concordância forte’ e 'concordância total' da escala do tipo Likert. Os números encontrados perfazem o total de cada variável e se referem à média positiva da escala, permitindo visualizar os aspectos adequadamente avaliados pelos alunos. $\mathrm{O}$ alfa de Cronbach é de 0,518. Foi composta por 30 afirmativas distribuídas em cinco variáveis denominadas de 'sustentabilidade’; ‘aprendizado’; ‘família’; ‘escola’; e ‘atividade’.

Tabela 7 - Estatística descritiva para o total das variáveis

\begin{tabular}{|l|c|c|c|}
\hline \multicolumn{1}{|c|}{ Variáveis } & N & Média & Desvio-padrão \\
\hline Sustentabilidade & 578 & 4,85 & 0,872 \\
\hline Aprendizado & 578 & 5,16 & 1,061 \\
\hline Família & 578 & 5,14 & 1,032 \\
\hline Escola & 578 & 5,40 & 0,926 \\
\hline Atividade & 578 & 5,01 & 1,055 \\
\hline
\end{tabular}

Fonte: Elaborados pelos autores 'busco me informar sobre a destruição da natureza e do planeta’ (média 4,94 e desvio-padrão 1,611), apresentam similaridade com os valores da variável família, simbolizada pela afirmativa principal 'a família deve possibilitar ensinamentos sobre como consumir sem agredir o meio ambiente' (média 5,55 e desvio-padrão 1,396). Os valores da variável aprendizado são também semelhantes aos da variável escola, representada pela frase principal 'a escola tem mais condições estruturais de ensinar sobre sustentabilidade ambiental do que a família’ (média 5,48 e desvio-padrão 1,577). A seguir, os números totais de cada variável.

De acordo com Hair et al. (2005), a correlação de técnica estatística empregada neste estudo é definida como de análise multivariada, utilizada para medidas de associação simples entre variáveis ordinais, aquelas que não possuem distribuição normal, ou seja, apresentam baixos níveis de associação estatística. Observa-se, com frequência, a intensidade de relacionamento entre as variáveis, podendo ser forte, fraco ou inexistente, e alguma forma de dependência entre elas.
De maneira complementar, buscou-se saber se as variáveis apresentavam relação recíproca significante por meio da correlação de Pearson. Os cálculos indicaram que todas as variáveis possuem relação entre si. No entanto, observou-se que 'aprendizado' e 'atividade' são variáveis expressas mais significativamente na família do que na escola, conforme a Tabela 8.
A variável sustentabilidade, representada pela afirmação principal 'tenho conhecimento sobre práticas de sustentabilidade' (média de 4,90 e desvio-padrão 1,417), demostrou que há um entendimento entre os respondentes sobre o tema abordado. Da mesma forma, a variável atividade, simbolizada pela locução 'preocupome com a sustentabilidade do planeta; por isso, procuro contribuir para a melhoria da qualidade de minha vida e de outras pessoas' (média 5,21 e desvio-padrão 1,556), confirmou que os jovens se envolvem, sem muita ênfase, em ações práticas de sutentabilidade. Os valores da variável aprendizado, expressa pela declaração
Tabela 8 - Fatores que apresentam correlação significante entre si.

\begin{tabular}{|lccc|}
\hline \multicolumn{3}{|c|}{ Variáveis } & \multicolumn{3}{c|}{ Correlação de Pearson (variáveis) } \\
\hline & Sustentabilidade & Família & Escola \\
\hline Sustentabilidade & 1 & $0,309^{* *}$ & $0,337^{* *}$ \\
\hline Aprendizado & $0,298^{* *}$ & $0,520^{* *}$ & $0,413^{* *}$ \\
\hline Atividade & $0,341^{* *}$ & $0,491^{* *}$ & $0,464^{* *}$ \\
\hline **Correlação é significativa a0 nível 0,01 (2-tailed). & \\
\hline
\end{tabular}

Fonte: Elaborada pelos autores. 


\section{Discussões E CONSIDERAÇõES FINAIS}

O propósito deste estudo foi identificar o contexto, escolar ou familiar, de maior envolvimento das gerações Y e Z na apropriação do conhecimento sobre sustentabilidade.

Embora o conjunto dos resultados possa ser considerado relevante, conforme dados estatísticos anteriormente apresentados, devem ser destacados alguns aspectos, basicamente por se tratar de um estudo com duas gerações diferentes como agentes sociais respondentes. No âmago da discussão a seguir estão os resultados que apresentaram percentuais de participação mais expressivos e aqueles que geraram conflitos entre as gerações.

Em relação ao local ideal para o aprendizado de temas de sustentabilidade, ambas as gerações entendem ser o contexto escolar o mais indicado. É um entendimento contrário àquele em que houve a indicação - por parte de ambas as gerações - da família como a instituição que tem mais condições de ensinar sustentabilidade. Reside aí um aspecto importante para o entendimento da influência no comportamento de compra. A escola é um espaço onde deve ocorrer o processo ensino-aprendizagem e as gerações $\mathrm{Y}$ e $\mathrm{Z}$ observam dessa maneira, mas entendem que o ambiente familiar é o mais propício para o ensino do tema sustentabilidade. Isso demonstra, ainda que no campo da percepção, que os alunos de ambas as gerações podem estar mais propensos ao aprendizado do tema específico fora dos corredores escolares. Autores como Osajima, Sternquist e Manjeshwar (2010); Hanzaee e Aghasibeig, (2008); Bakewell e Mitchell (2003) acreditam que os participantes dessas gerações pouco dialogam ou acreditam nos pais, o que contraria os achados desta pesquisa.

Quanto ao entendimento de quem tem mais condições de ensinar aspectos do tema sobre a sustentabilidade, as gerações Y e Z enfatizaram a influência da família sobre a escola, tendo a geração $Y$ participado mais positivamente (com 59,3\%, contra os 54,4\% da geração Z). Ambas entendem que é a família a principal base para a construção e a disseminação do conhecimento na área, embora os percentuais apresentados sejam bastante próximos aos da variável escola. Como toda construção cultural é sempre social e individual, segundo Simmel (1971), infere-se que a manifestação cultural é individual, mas sempre alicerçada em estruturas sociais. Ou seja, embora o consumo possa ser individual, como comprador, tende a seguir normas sociais, tanto formais quanto informais.

Quando se quis saber sobre o espaço mais adequado para o aprendizado da correta separação do lixo, a geração Y elegeu a instituição escola, enquanto a geração $\mathrm{Z}$ escolheu a família, com praticamente os mesmos percentuais, demonstrando claramente o caminho dicotômico alcançado pelas duas gerações. Nesse sentido, Holbrook e Hirschman (1982) defendem que consumidores de diferentes idades podem apresentar avaliações diferenciadas a respeito das coisas, tangíveis ou intangíveis. Além disso, a geração $\mathrm{Y}$ pode estar interagindo mais com a escola, em uma ação própria de 'libertação’ das amarras familiares.

Na questão de saber se é a escola que deve se articular com a família ou se é a família que deve envolver a escola nos projetos do ensino do tema sustentabilidade, as respostas obtidas revelaram a afirmativa positiva de ambas as gerações de que a família é o principal ente articulador: a geração Y, com 54,5\%, e a geração Z, com $81,8 \%$. Novamente, o que chama atenção é a ampla participação da família nos desígnios diversos da geração $\mathrm{Z}$, nesse caso, com a maioria das respostas. Se abordadas em conjunto, as assertivas demonstram a ênfase na força da família sobre os hábitos atuais e futuros de consumo dos alunos. Para Mainardi e Pessotto (2010), cabe aos pais, inicialmente, a missão de transformar os filhos, inexperientes, em pessoas que ajam com responsabilidade em relação ao seu meio e que consigam compreender as melhores decisões a serem tomadas para benefício futuro. Assim, dependendo da maneira como é compreendida e disseminada a sustentabilidade, os encontros e as conversas familiares podem afetar o comportamento dos estudantes.

Quanto à questão de dar exemplos sobre sustentabilidade, ocorreu uma inversão. Ambas as gerações entendem ser a escola (71,0\% na geração Y e 80,0\% na geração Z) a principal instituição a cumprir 
essa tarefa. Isso demonstra, conforme pregam Mainardi e Pessotto (2010), que o entendimento popular de que a escola é o grupo que ‘ensina', tirando a responsabilidade da família ou fazendo-a eximir-se da ação, é cada vez mais comum. Para Baudrillard (1995), o indivíduo atual passa a dispor de capital simbólico ampliado para construir e desconstruir o seu estilo de vida no desempenho de um papel social, e isso passa sempre pela escola, visto sua idade cronológica. Se em questão anterior as gerações afirmaram que a família teria mais condições de ensinar sustentabilidade $(59,3 \%$ e $54,4 \%$, respectivamente gerações $\mathrm{Y}$ e Z) por qual motivo entendem que os exemplos devam partir da escola $(71,0 \%$ e 80,0\%, respectivamente gerações Y e Z)? Essa constatação retrata uma característica da geração: a dificuldade de interação social, inclusive com a família, condição já defendida por autores como Osajima, Sternquist e Manjeshwar (2010); Hanzaee e Aghasibeig, (2008); Bakewell e Mitchell (2003). Já Baudrillard (1995) advoga a ideia de que a cultura midiática colocou o consumo como elemento central para a mudança no estilo de vida e trouxe conjuntamente uma demanda crescente por renovação e ruptura, dificultando algumas interações sociais com grupos de idades diferentes. Para além dessa diferença existente, percebe-se no conflito de entendimento que as gerações buscam estilos de vida diversos que rompam com os padrões estabelecidos, afetando diretamente os procedimentos de decisão e consumo, atuais e futuros.

O comportamento das gerações estudadas é orientado por alta absorção de informação, com os acontecimentos noticiados em tempo real. Para Shah (2009), o volume intenso de informação se torna obsoleto em pouco tempo para indivíduos dessas gerações, o que acarreta insatisfação e sensação de lacuna, movendo os jovens à busca de mais informações e mais envolvimento virtual, em um ciclo repetitivo. Importante contribuição nesse sentido dá Goffman (2005), ao afirmar que existem traços fundamentais constituintes da modernidade, em que os indivíduos vivenciam mais plenamente a experiência de se construírem como pessoas por meio de redes sociais e outras ferramentas interativas. Autores como Simmel (1971) e Weber (2000) confirmam essa interpretação quando defendem a existência de um caráter significativo nas ações sociais, com os atores desempenhando seus papéis em jogos interativos. Dessa maneira, para a geração $\mathrm{Y}$ a escola tem a responsabilidade de educar e disseminar conhecimento sobre diversas áreas, inclusive sustentabilidade. Por sua vez, a geração Z compreende que a família deve compartilhar conceitos específicos, tais como ensino do uso da água, dos meios de evitar o desmatamento e da separação do lixo.

Os achados mostram que na decisão de compra e consumo a geração $\mathrm{Y}$ é mais influenciada pela escola do que pela família, comportamento contrário à geração $\mathrm{Z}$, que mais vezes salientou a importância da família no processo. Para Bourdieu (2007), são os indivíduos, sozinhos, que decidem e constroem sua realidade social, cujos valores que carregam, em muitos aspectos, condicionam as escolhas e as possibilidades de formação do indivíduo como pessoa. A relevância dessa constatação se dá tanto para estudos acadêmicos quanto para ações no campo profissional.

Pesquisadores, de imediato, podem desenvolver estudos que permitam a construção de conhecimento relacionado aos diferentes comportamentos de decisão de compra e sua conexão com outras temáticas, tais como identidade de marca, efetividade da propaganda ou reconhecimento da marca, em situações em que estejam envolvidos os preceitos teóricos de sustentabilidade.

Nesse sentido, também as organizações devem estar atentas ao comunicar os seus valores de natureza sustentável à comunidade. A denominada cultura do consumo é caracterizada pela capacidade de significação dos bens materiais e posterior produção de sentido. Para Baudrillard (1995), os bens sempre foram simbólicos, mas neste momento se consagram, como ocorre quando uma marca se transforma em conceito. Para diversos autores (Douglas e Isherwood, 2006; Holbrook e Hirschman, 1982; McCracken, 1986), a noção experiencial do consumo é caracterizada por um fluxo de fantasias, sentimentos e diversão, basicamente o prazer hedônico vindo de atividades prazerosas. Por exemplo, os esforços midiáticos massivos se voltarão cada vez mais para essas gerações, no entendimento de Morin (1987), tanto no campo da imagem quanto de outros símbolos, como a música. Sendo a escola mais atuante do que a família 
nesse aspecto, a comunicação pode ter natureza mais didática, emparelhando-se ao formato adotado em sala de aula pelos professores. Ao mesmo tempo, a conexão entre os docentes e as organizações deve estar mais afinada, limitando a eles a possibilidade de compreenderem apenas o ponto de vista comercial (compra e venda), e assim perder de vista as ações de responsabilidade social corporativa adotadas pelas organizações. Para Huang e Rust (2011), ideias afinadas podem conduzir organizações e sociedade para um futuro mais próspero.

Entre as limitações do estudo está a proximidade das idades dos respondentes, sendo, possivelmente, uma das razões dos apontamentos similares entre as gerações. Para novas pesquisas, sugerem-se amostras compostas por escolas de regiões diferentes, com apelo urbano mais avançado, tais como as capitais dos estados, para comparação dos hábitos de consumo e sua relação com o consumo consciente. Outra limitação refere-se à ausência de pesquisa qualitativa, que traria relevância no aprofundamento dos achados. Ao mesmo tempo, parece instigante saber as diferenças que podem ser expressas ao se estudar os níveis superior e médio, considerando ambas as gerações.

\section{REFERÊNCIAS}

BASÍLIO, A. C.; FÉLIX, J. D. B. O comportamento do consumidor jovem em relação à responsabilidade socioambiental e a necessidade da comunicação para a sustentabilidade. Revista Universitas/Comunicação, Brasília, v. 7, n. 2, p. 1-27. 2010.

BAKEWELL, C.; MITCHELL, V. W. Generation Y female consumer decision-making styles. International Journal of Retail and Distribution Management, v. 31, n. 2. 2003. $<$ http://dx.doi.org/1758-6690>

BHATTACHARYA, C. B.; KORSCHUN, D.; SEN, S. Strengthening stakeholder-company relationships through mutually beneficial corporate social responsibility initiatives. Journal of Business Ethics, v. 85, p. 257-272. 2009. <http:// dx.doi.org/10.1007/s10551-008-9730-3>

BESSA, N. G. F.; COSTA, F. P. Sustentabilidade na perspectiva de uma educação transformadora e cidadã: um estudo de caso a partir de uma escola do Município de Gurupi (TO). Revista Cereus, v. 1, n. 1, agosto de 2009.
BAUDRILLARD, J. A sociedade de consumo. Lisboa: Edições 70, 1995.

BOURDIEU, P. A distinção: crítica social do julgamento. São Paulo: Edusp, 2007.

BURSZTYN, M.; BARTHOLO Jr., R. S. Prudência e utopismo: ciência e educação para a sustentabilidade. Revista Ciência, Ética e Sustentabilidade. Brasília, DF: UNESCO, 2001.

DOUGLAS, M.; ISHERWOOD, B. O mundo dos bens: para uma antropologia do consumo. Rio de Janeiro: Editora UFRJ, 2006.

ELKINGTON, J. Cannibals with forks: the triple bottom line of 21st century business. Oxford: Capstone, 2000.

FREITAS, W. R. S.; JABBOUR, C. J. C.; GOMES, A. F. Gestão ambiental: um novo desafio para os profissionais de recursos humanos? Revista Cesumar Ciências Humanas e Sociais Aplicadas, v. 16, n. 1, p. 29-47. 2011.

GADOTTI, M. Educar para a sustentabilidade. Revista Inclusão Social, Brasília, v. 3, n. 1, p. 75-78. 2008.

GAUVREAU, K.; PAGANO, M. Why 5\%? Nutrition, v. 10, n. 1, p. 93-94. 1994.

GOFFMAN, E. A representação do eu na vida cotidiana. Petrópolis: Vozes, 2005.

GONÇALVES-DIAS, S. L. F.; Teodósio, A. S. S.; Barbieri, J. C. Desafios e perspectivas da sustentabilidade: caminhos e descaminhos na gestão empresarial. In: ENCONTRO NACIONAL SOBRE GESTÃO EMPRESARIAL E MEIO AMBIENTE, 9, 2007, Curitiba. Anais do IX ENGEMA. Curitiba, 19 a 21 de novembro de 2007.

GONÇALVES-FILHO, C.; BRITO, H.; GOSLING, M.; SOUKI, G. Q. Os impactos da responsabilidade social corporativa na reputação da empresa e nas intenções comportamentais das comunidades: estudo empírico. Contextus Revista Contemporânea de Economia e Gestão, v. 7, n. 1, p. 37-54. 2009.

HAIR Jr., J. F.; ANDERSON, R. E.; TATHAM, R. L.; BLACK, W. C. Análise multivariada de dados. 5. ed. Porto Alegre: Bookman, 2005.

HANZAEE, K. H.; AGHASIBEIG, S. Generation Y female 
and male decision-making styles in Iran: are they different? The International Review of Retail, Distribution and Consumer Research, v. 18, n. 5. 2008. <http://dx.doi. org/10.1080/09593960802573443>

HOLBROOK, M. B.; HIRSCHMAN, E. C. The experiential aspects of consumption: Consumer fantasies, feelings, and fun. Journal of Consumer Research, v. 9, n. 2, p. 132-140. 1982. $<$ http://dx.doi.org/10.1086/208906>

HOLLAND, A. Sustainability. In: JAMIESON, D. (Org.). A companion to environmental philosophy. London: Blackwell, 2003.

HOPKINS, C.; McKEOWN, R. Education for sustainable development: an international perspective. In: TILBURY, D. et al. Education and sustainability: responding to the global challenge. Gland, Switzerland: IUCN, CEC, 2002.

HUANG, M-H; RUST, R. T. Sustainability and consumption. Journal of the Academy of Marketing Science, v. 39, p. 4054. 2011. <http://dx.doi.org/10.1007/s11747-010-0193-6>

HUDSON, S. Wooing zoomers: marketing to the mature traveler. Marketing Intelligence \& Planning, v. 28, n. 4, p. 444-461. 2010. <http://dx.doi.org/10.1108/02634501011053568>

JACOBI, P. Educação ambiental, cidadania e sustentabilidade. Cadernos de Pesquisa Fundação Carlos Chagas, n. 118, p. 189-205, 2003.

LEFF, E. Epistemologia ambiental. São Paulo: Cortez, 2001.

MAIA, A. G.; PIRES, P. S. Uma compreensão da sustentabilidade por meio dos níveis de complexidade das decisões organizacionais. Revista de Administração Mackenzie, v. 12, n. 3, p. 177-206. 2011.

MAINARDI, R.; PESSOTTO, R. B. M. Escola e família: uma união imprescindível. In: Psicopedagogia em debate (e-book), série Pesquisa em Ciências Humanas, Org.: FINK, A. T.; FERRARI, R. F.; CANAN, S. R. Frederico Westphalen (RS), p. 101-113, 2010.

McCRACKEN, G. Culture and consumption: a theoretical account of the structure and movement of the cultural meaning of consumer goods. Journal of Consumer Research, v. 13, n. 1, p.71-84. 1986. <http://dx.doi.org/10.1086/209048>

MORIN, E. Cultura de massas do século XX: o espírito do tempo. Rio de Janeiro: Forense Universitária, 1987.
MOWEN, J. C.; MINOR, M. S. Comportamento do consumidor. 1 $^{\text {a }}$ ed. São Paulo: Prentice Hall, 2003.

OSAJIMA, K.; STERNQUIST, B.; MANJESHWAR, S. Japanese materialism: a comparison between the new breed and second baby-boomer age-cohorts. Journal of Asia Business Studies, v. 4, n. 2, 2010. <http://www.emeraldinsight.com/ journals.htm?articleid=1865416\&show=abstract $>$

REGO, T. C. Memórias de escola: cultura escolar e constituição de singularidades. Petrópolis, RJ: Vozes, 2003.

SAVITZ, A. W.; WEBER, K. The triple bottom line: how today's best-run companies are achieving economic, social and environmental success and how you can too. San Francisco: John Willey \& Sons, 2006.

SCHARF, E. R.; CUNHA, H. Mindful comsumption as marketing competitive advantage: the strength of ideology toward the purchase decision. In: AMS 40th Conference 2011: The sustainable global marketplace. Procedures..., Coral Gables, p. 81-86, 2011.

SCHARF, E. R.; SORIANO-SIERRA, E. J. A gestão do conhecimento na educação ambiental: a integração das escolas primária e secundária com a universidade para um futuro melhor. Revista Angrad, v. 7, n. 1, p. 9-22. 2006.

SHAH, G. The impact of economic globalization on work and family collectivism in India. Journal of Indian Business Research, v. 1, n. 2/3, p. 95-118. 2009. <http://dx.doi. org/10.1108/17554190911005318>

SIMMEL, G. On individuality and social forms. Chicago: The University of Chicago Press, 1971.

VASCONCELOS, K. C. A.; MERHI, D. Q.; LOPES, V. M. G.; SILVA, A. R. L. A geração Y e suas âncoras de carreira. II Encontro de Gestão de Pessoas e Relações de Trabalho (EnGPR), Curitiba (PR). Anais... Curitiba: ANPAD, 2009.

WADA, E. K.; CARNEIRO, N. A. As necessidades da geração Y no cenário de eventos empresariais. Contribuciones a la Economía, Málaga, Espanha: 2010. Disponível em: <http:// www.eumed.net/ce/2010a/kwac.htm> Acessado em 20/ set/2011.

WEBER, M. Economia e sociedade, v. 1 e 2. Brasília: UNB, 2000. 